\title{
Computational study of the performance of the Etoile flow conditioner
}

\author{
Mohamed Aichouni ${ }^{1}$, Lioua Kolsi 1, 2, *, Noureddine Ait-Messaoudenne 1, Walid Aich 1, 3 \\ ${ }^{1}$ The Engineering College, University of Hail, PO Box 2440, Hail, Saudi Arabia \\ 2Unité de recherche de Métrologie et des Systèmes Energétiques, Ecole Nationale d'Ingénieurs, 5000 Monastir, University of \\ Monastir, Tunisia \\ ${ }^{3}$ Unité de Recherche Matériaux, Energie et Energies Renouvelables, Faculté des Sciences de Gafsa, Tunisie
}

\section{A R T I C L E I N F O}

\section{Article history:}

Received 10 June 2016

Received in revised form

11 August 2016

Accepted 17 September 2016

\section{Keywords:}

Computational fluid dynamics

Flow conditioners

Pipe flow

Fully developed flow

ISO 5167

Flow rate measurements

\section{Background and literature review}

Flow rate measurements have always been an important industrial operation for process control and fiscal purposes. The ability to accurately measure the flow rate in a duct is of a major concern and vital importance when large volumes of fluids are handled. Gas and Petroleum companies recorded receipts of billions of barrels or cubic meters of gas and petroleum over a period of a year. The quality of gas measurement, receipt and major delivery points distributed through thousands of kilometers of pipe lines, is very important from an economical and technological stand points. Errors in flow measurement can have large cost and efficiency implications.

For accurate flow measurements, industrial flow meters must be calibrated. This is done in fully developed pipe flow, axisymmetric, free from swirl and pulsation. Standards such as ISO 5167:2003 and ANSI/API 2530 AGA 3 define a satisfactory flow as one which has a swirl angle less than two degrees and for which the axial mean velocity is within $\pm 5 \%$

\footnotetext{
* Corresponding Author.

Email Address: lioua enim@yahoo.fr (L. Kolsi)

https://doi.org/10.21833/ijaas.2016.09.005

2313-626X/@ 2016 The Authors. Published by IASE.

This is an open access article under the CC BY-NC-ND license

(http://creativecommons.org/licenses/by-nc-nd/4.0/)
}

\begin{abstract}
A B S T R A C T
conditioners serve to reduce the developing length betwe means for metering errors reduction and elimination. The author flow conditioners to optimize their performance in reducing flow proposed design settings. Powerful Computational Flow Dynamics flow conditioners.
\end{abstract}

(C) 2016 The Authors. Published by IASE. This is an open access article under the CC BY-NC-ND license (http://creativecommons.org/licenses/by-nc-nd/4.0/).

of the corresponding fully developed profile measured in the same pipe after 100 pipe diameter of development length. Given that most industrial installations include pipe fittings such as bends, valves, expanders and reducers, which are sources of both swirl asymmetries and turbulence distortions, insuring that fully developed flow in terms of mean flow and turbulence structure approaches the meter is difficult to achieve in practical and industrial situations. While high accuracy about $\pm 0,1 \%$ flow rate measurement is required, disturbances in the flow caused by contractions, bends, and other components introduce metering errors of the order of $\pm 5 \%$ and greater (Aichouni et al., 1996; Merzkirch, 2001; Sawchuk, 2016).

For acceptable accuracy, a flow meter needs to be presented with an axisymmetric, fully developed velocity profile with zero swirls. Either very long lengths of straight pipe work upstream of the meter must be provided (recommended by ISO 5167) and these may need to be of the order of 80 to 100 pipe diameters, which will give a higher installation cost and greater space requirement. Alternatively, upstream disturbances can be attenuated by using flow conditioners or flow straighteners to control the quality of the flow approaching the metering device.

A fundamental understanding of the approaching velocity profiles and their effects on the discharge coefficient of a metering device is an essential 
knowledge for the optimum design of a flow conditioner-meter package that minimizes installation effects and increases metering performances of these devices. Since early 1980`s concentrated research work has been undertaken at international laboratories and research institutes (Morrow et al., 1991; Gajan and Hebrard, 1991; Morrison et al., 1992; Laws and Ouazzane, 1994; Merzkirch, 2001; Aichouni and Laribi, 2000; Laribi et al., 2003; Gersten, 2008; Laribi et al., 2012; Manshoor and Amir, 2012; Brown and Griffith, 2013) Sawchuck, 2016). It has been focused to investigate experimentally and computationally installation effects on industrial flow meters and the efficiency of flow conditioners to minimize the installation effects on flow meters accuracy. Most of these studies investigated the effect of flow conditioner location with respect to the flow meter on its calibration coefficients. The major conclusions showed that the distortions in the approaching flow generated by pipe fittings upstream the meter can cause significant shifts in the meter's calibration coefficient, hence leading to considerable errors in flow metering. In early papers presented by Aichouni et al. (1996, 2000) and Laribi et al. (2003, 2012), experimental and numerical results on installation effects upon differential pressure flow meters were discussed, and the performance of flow conditioners to produce the fully developed flow condition and to reduce metering errors were presented. Frattolillo and Massarotti (2002) compared numerically the performance of different flow conditioners, independently from their effects on particular flowmeters. The main fundings of their work were that the etoile presents good characteristics in term of swirl, but the flatness and asymmetry relative efficiencies are not very high and the tube bundle shows very good performance in terms of symmetry, but it also shows a large disturbance of the axial velocity profile.

Though extensive research has been carried out worldwide, there is still a need for fundamental understanding of the flow behavior within this industrial metering setting. The present research project falls within this perspective and the international scientific efforts towards the understanding of the flow development and the efficiency of flow conditioners to remove flow distortions and to produce the standard fully developed condition. In the present paper, we will discuss the numerical predictions of the Etoile flow straightener described in the international standards ISO 5167(R:2014) and ANSI/API 2530 AGA 3. A particular focus will be made on the effect of the length of the Etoile straightener on the flow development towards the fully developed flow condition.

\section{Geometry, mathematical model and numerical method}

Fig. 1 shows the geometry studied and the grid used. The flow conditioners studied is positioned immediately downstream from the second elbow.

The Reynolds number Re, is defined as follows (Eq. 1):

$$
R e=\rho U_{i} D_{h} / \mu
$$

The flow in the pipe is supposed to be steady and the fluid is incompressible; the time mean averaged equations for conservation of mass and momentum have been used together with the standard $\mathrm{K}-\varepsilon$ turbulence model to set a closed system of partial differential equations to predict the flow development downstream flow conditioners.

The steady three-dimensional differential equations governing the phenomenon can be written as follows:

Continuity equation (Eq. 2):

$$
\frac{\partial u_{i}}{\partial x_{i}}=0
$$

Momentum equation (Eq. 3):

$$
\frac{\partial \rho u_{i} u_{j}}{\partial x_{i}}=\frac{\partial}{\partial x_{j}}\left[\left(\mu+\mu_{t}\right)\left(\frac{\partial u_{i}}{\partial x_{j}}+\frac{\partial u_{j}}{\partial x_{i}}\right)-\delta_{i j} \frac{2}{3} \frac{\partial u_{k}}{\partial x_{k}}-\frac{\partial\left(\delta_{i j} P\right.}{\partial x_{j}}\right]
$$

Turbulent kinetic energy equation (Eq. 4):

$$
\frac{\partial_{\rho u_{j} K}}{\partial x_{j}}=\frac{\partial}{\partial x_{j}}\left[\left(\mu+\frac{\mu_{t}}{P r_{K}}\right) \frac{\partial K}{\partial x_{j}}\right]+\mu_{t} \frac{\partial u_{j}}{\partial x_{i}}\left(\frac{\partial u_{i}}{\partial x_{j}}+\frac{\partial u_{j}}{\partial x_{i}}\right)-\rho \varepsilon
$$

Dissipation rate of turbulent kinetic energy (Eq. 5):

$$
\frac{\partial_{\left(\rho u_{j} \varepsilon\right)}}{\partial x_{j}}=\frac{\partial}{\partial x_{j}}\left[\left(\mu+\frac{\mu_{t}}{P r_{\varepsilon}}\right) \frac{\partial \varepsilon}{\partial x_{j}}\right]+\frac{C_{1} \varepsilon \mu_{t}}{K} \frac{\partial u_{i}}{\partial x_{j}}\left(\frac{\partial u_{i}}{\partial x_{j}}+\frac{\partial u_{j}}{\partial x_{i}}\right)-\frac{C_{2} \rho \varepsilon^{2}}{K}
$$

The turbulent viscosity is defined as (Eq. 6):

$$
\mu_{t}=\frac{C_{\mu} \rho \varepsilon^{2}}{K}
$$

with:

$$
C_{\mu}=0.09, C_{1}=1.47, C_{\mu}=1.92, P r_{K}=1, P r_{\varepsilon}=1.3
$$

(Launder (1972))

Boundary conditions:

- $u=0, v=0, w=0$, at all tube walls

- $w=U_{i}, K=K_{i}, \varepsilon=\varepsilon_{i}$, at the inlet;

- $\frac{\partial}{\partial n}\left(u_{i}, T, K, \varepsilon\right)=0$ at the outlet.

The governing equations for the turbulent pipe flow configurations were solved using the COMSOL Muti-physics CFD code; further details about the numerical procedure can be found in Elashmawy and Kolsi (2016).

Numerical predictions were tested at different mesh sizes and grid -independent solutions were obtained with the grids presented in Table 1. 
Table 1: Number of meshing elements

\begin{tabular}{|c|c|}
\hline Configuration & Meshing Elements \\
\hline 1D & 915919 \\
\hline $0.5 \mathrm{D}$ & 803954 \\
\hline $0.25 \mathrm{D}$ & 755123 \\
\hline $0.125 \mathrm{D}$ & 713785 \\
\hline
\end{tabular}

\section{Results and discussions}

Flow conditioners serve for reducing the developing length between pipe fittings and flow meters and to create the fully developed flow condition within short distance, hence leading to reduction of the metering errors. In the present study, numerical predictions of the flow development downstream the Etoile flow conditioner will be presented and discussed.

The initial flow conditions were set to be severely distorted by a $90^{\circ}$ double bend which precedes the flow conditioner. The flow was allowed to develop further in a straight pipe up to 100 pipe diameters. The simulated flow configuration is shown in Fig. 1.
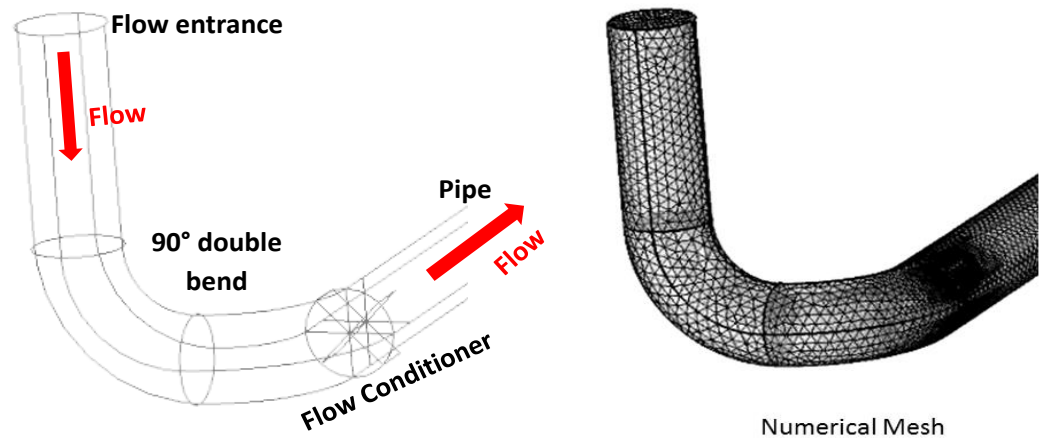

Fig. 1: Flow configuration and computational mesh

Predictions of the mean flow and turbulent structures downstream the flow conditioner was obtained and analyzed.

Fig. 2 shows the axial mean velocity contours downstream the Etoile flow conditioner with three geometrical configurations (i.e. the standard 2 diameters long flow conditioner $(\mathrm{L}=2 \mathrm{D})$ and $\mathrm{L}=\mathrm{D}$ and $\mathrm{L}=\mathrm{D} / 4)$. The Fig. shows that the double bend generates a highly distorted flow with a pronounced asymmetry and highly sheared flow, which is associated with high swirl (up to \pm 8 degrees) and high turbulence levels. A pronounced wake can be noticed at the central region of the pipe which is generated by the solid part of the flow conditioner at the center. The wake associated with the initial flow distortion seems to take several pipe diameters to be attenuated. I is to be noted here that the ISO international standards recommends swirl angle limits for accurate flow metering to be \pm 2 degrees. Standard Geometry L = 2 D

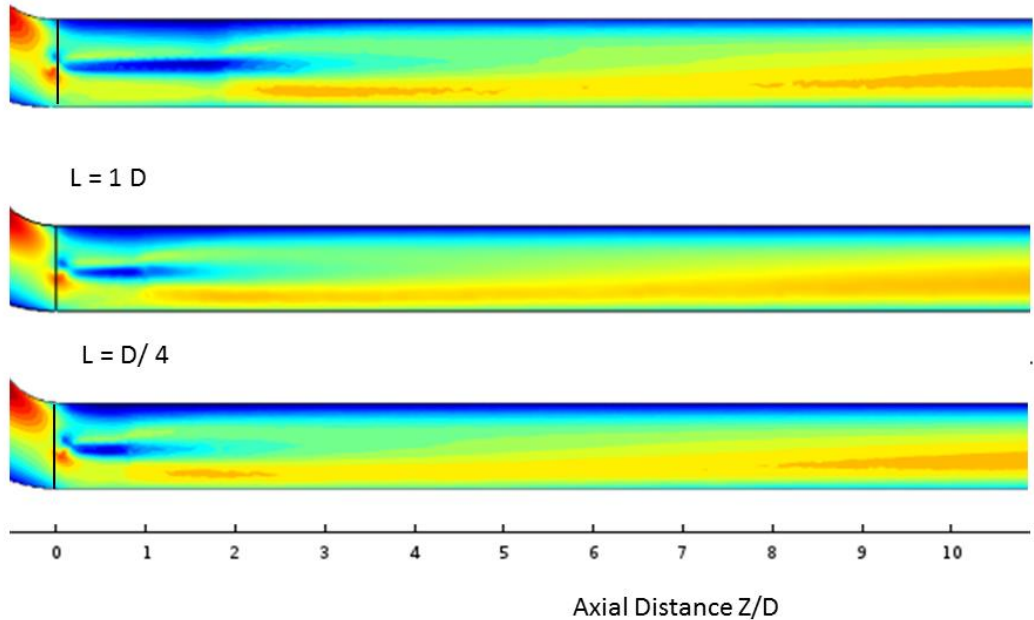

Fig. 2: Predicted flow development downstream the three flow conditioner configurations

It can also be seen from these Figures that though the flow at the vicinity of the flow conditioner depends on the conditioner geometry (Length), at a downstream distances of 10 diameters it does not seem to attend the fully developed profile. The effect of the flow distortion and the swirl still exist after that distance of straight flow development. Early experimental work presented by Laws and Ouazzane (1994) and Brown and Griffith (2013) showed that there is a possibility to produce fully developed flow condition within such manageable and economical distance. However, the authors believe that a standards flow conditioner with this excellent performance is not yet designed. More research 
would be needed towards that purpose. In the present paper we were interested to assess the effectiveness of the standard (2D length) Etoile flow straightener on the flow distortion and swirl attenuation towards the fully developed flow condition. Also, the question of the effect of the length of the Etoile on its performance was examined. Though, five configurations were tested during the project (flow straightener with length of 2D, D, D/2, D/8 and D/16), in the present study, only the results of $\mathrm{L}=2 \mathrm{D}, \mathrm{D}$, and $\mathrm{D} / 2$, will be presented and discussed. The predicted axial velocity profiles downstream the flow straightener are shown on Fig. 3 at different axial distance $(\mathrm{Z} / \mathrm{D}=4,8$, and 12$)$ and compared to the fully developed profile predicted at $\mathrm{Z} / \mathrm{D}=90$. This Figure shows clearly that the flow distortion generated by the double bend is still present after $12 \mathrm{D}$ of flow development for the tested straightener configurations $(2 \mathrm{D}, \mathrm{D}, \mathrm{D} / 2, \mathrm{D} / 8$ and $\mathrm{D} / 16)$. The velocity profiles still exhibit the asymmetry and the wake and the shear flow is still present. This can be seen from Fig. 4 where axial velocity profiles and swirl angle were plotted at different axial plans and compared to the fully developed profiles. From these observations, it can be suggested that the length of the Etoile flow straightener would not have a great effect on its performance in reducing flow distortions and disturbances. Hence it is recommended that the standards Etoile flow straightener would be used in industrial settings with flow meters. Early experimental work by Laribi et al. (2003) agree with this conclusion.

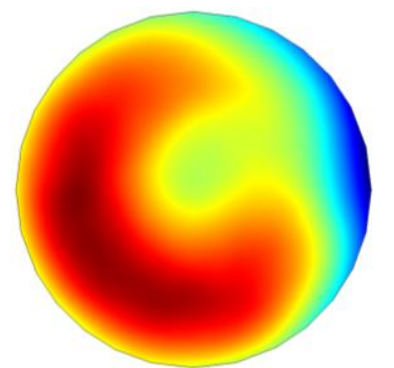

$\mathrm{Z} / \mathrm{D}=4$

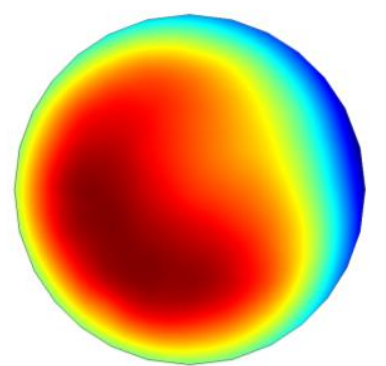

$\mathrm{Z} / \mathrm{D}=8$

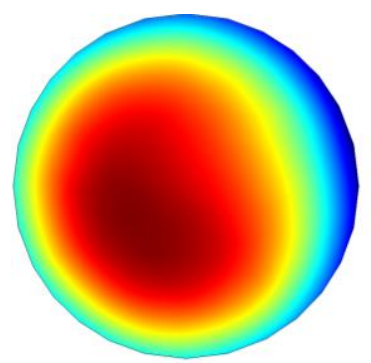

$\mathrm{Z} / \mathrm{D}=12$

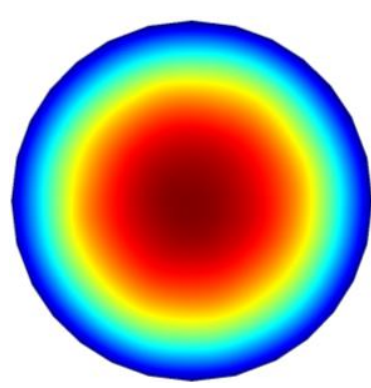

$\mathrm{Z} / \mathrm{D}=90$

(a) $L=2 D$

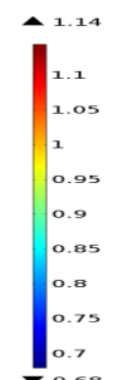

...
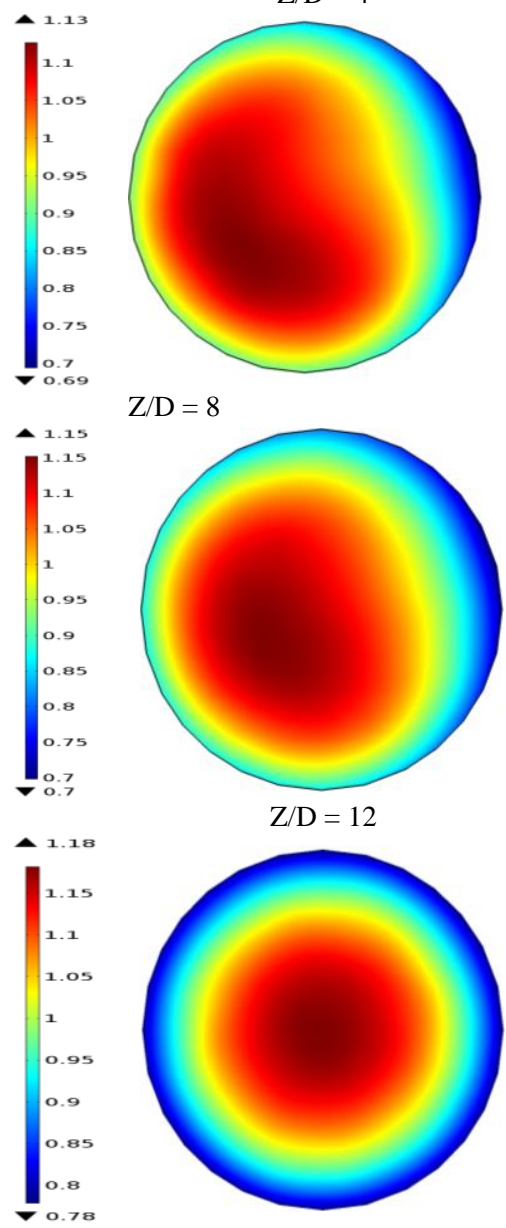

$\mathrm{Z} / \mathrm{D}=90$

(b) $L=D$

$\mathrm{Z} / \mathrm{D}=8$

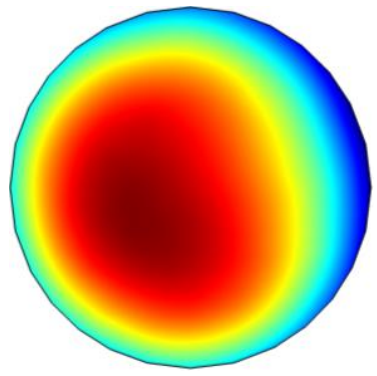

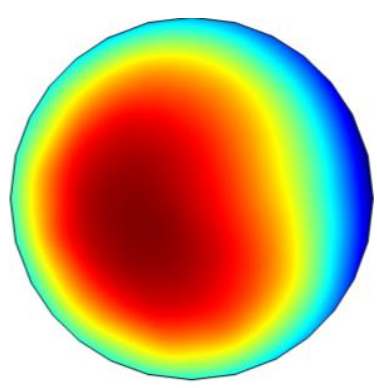

$\mathrm{Z} / \mathrm{D}=4$

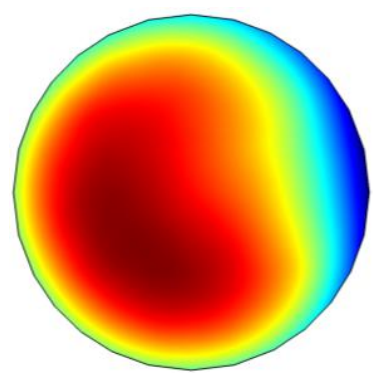

$\mathrm{Z} / \mathrm{D}=8$

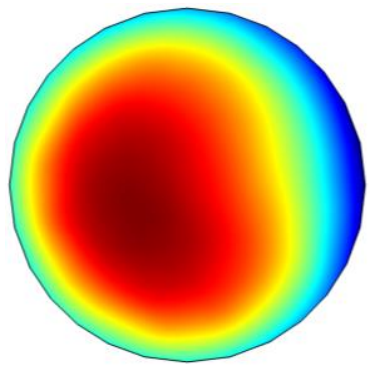

$\mathrm{Z} / \mathrm{D}=12$

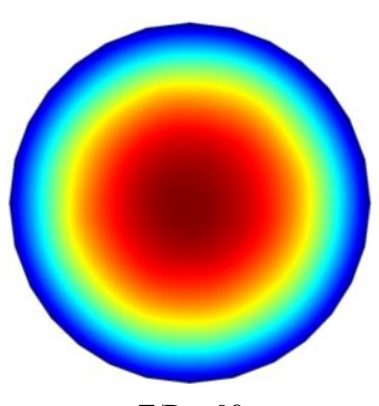

$\mathrm{Z} / \mathrm{D}=90$

(c) $L=D / 4$

Fig. 3: Predicted axial velocity at different axial positions $Z / D$ downstream the flow conditioner with three different geometries (L) compared to the fully developed profile 

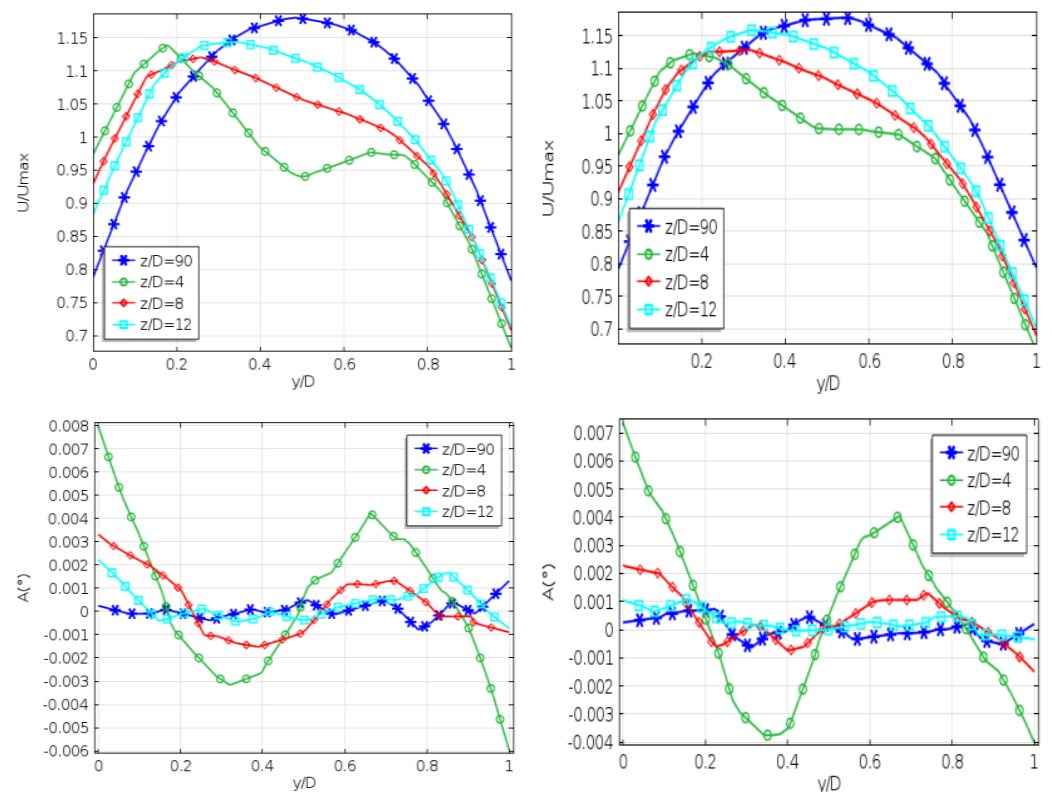

(a) $L=2 D$

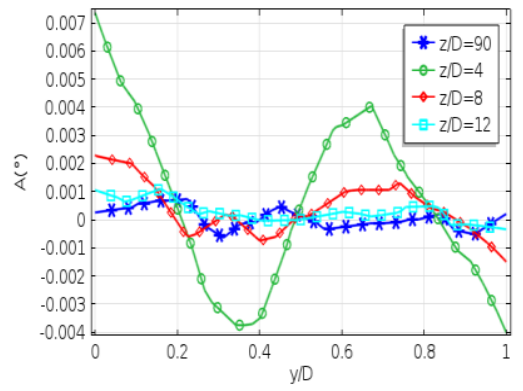

(b) $L=D$
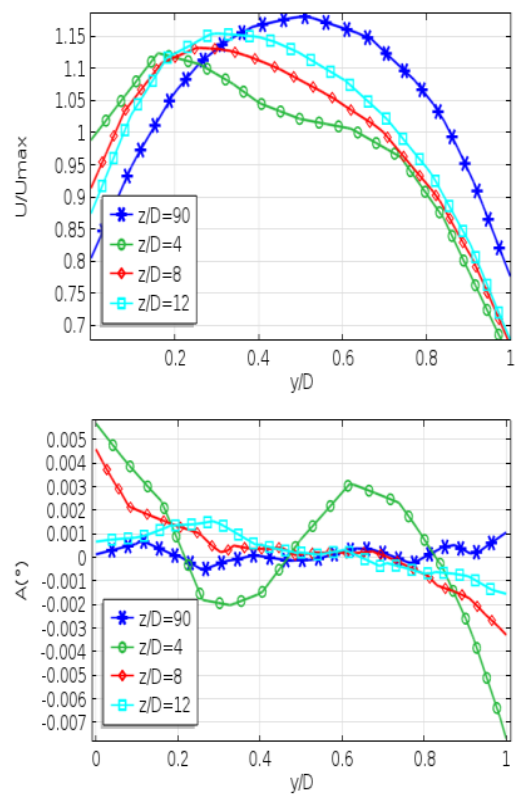

(c) $L=D / 4$

Fig. 4: Velocity profiles and Swirl Angle simulated at different axial position Z/D for different Length of the Etoile Straightener

\section{Conclusion}

Measurement of flow rate in non-standards flow conditions remains a problem of highly practical interest from both its technological and economic aspects. A great deal of experimental and numerical studies have been made in an effort to understand the fundamental of the fluid flow involved with the problem and propose practical solutions. Through this research work, computational fluid dynamics (C.F.D) techniques have been used to investigate the flow development downstream flow conditioners working under severe flow distortions. The performance to produce fully developed flow condition was investigated numerically. The tested flow conditioner was the Etoile flow straightener described in the standards ISO5167:2003 and ANSI/API 2530 AGA 3.

The effect of the length of the Etoile flow straightener with $((2 \mathrm{D}$ as described by the ISO 5167 standards), D, D/2, D/8 and D/16) on the flow performance was also investigated. The predictions show that the mean flow distortions were not removed after $12 \mathrm{D}$ of flow development for the 5 straightener configurations $(2 \mathrm{D}, \mathrm{D}, \mathrm{D} / 2, \mathrm{D} / 8$ and $\mathrm{D} / 16$ ) while the swirl seem to be removed by the straightener within the ISO limits of \pm 2 degrees. This indicates that the length of the Etoile flow straightener would not have a great effect on the flow performance, suggesting that the standard configuration of the Etoile flow straightener would be recommended for accurate industrial flow metering purposes.

\section{Acknowledgment}

The present work was undertaken within the research project (No: 0150164), funded by the
Deanship of Scientific Research, at the University of Hail. This is gratefully acknowledged.

\section{Nomenclature}

$\mathrm{C}_{1}, \mathrm{C}_{2}, \mathrm{C}_{3}$
$\mathrm{D}_{\mathrm{h}}$
$\mathrm{K}$
$\mathrm{p}$
$\mathrm{Re}$
$\mathrm{u}_{\mathrm{i}}$
$\mathrm{u}$
$\mathrm{v}$
$\mathrm{w}$
$\mathrm{x}_{\mathrm{i}}$

$\mathrm{Pr}_{\varepsilon}$
$\mathrm{Pr}_{\mathrm{K}}$
$\varepsilon$
$\delta_{i j}$
$\mu$
$\rho$
$\mathrm{i}$
$\mathrm{o}$
$\mathrm{t}$
$\mathrm{w}$

turbulent model constant Hydraulic diameter Turbulent kinetic energy, $\mathrm{m}^{2} / \mathrm{s}^{2}$ pressure, $\mathrm{Pa}$

Reynolds number, velocity component in i-direction, $\mathrm{m} / \mathrm{s}$ velocity component in radial direction, $\mathrm{m} / \mathrm{s}$ velocity component in circumferential direction, $\mathrm{m} / \mathrm{s}$

velocity component in flow direction, $\mathrm{m} / \mathrm{s}$ Cartesian coordinate in i-direction Greek symbols

inverse effect Prandtl number for $\varepsilon$ inverse effect Prandtl number for $\mathrm{K}$ dissipation ratio of turbulent kinetic energy, $\mathrm{m}^{2} / \mathrm{s}^{2}$

Dirac delta function dynamic viscosity of fluid, $\mathrm{kg} /$ (m s) density, $\mathrm{kg} / \mathrm{m} 3$

Subscripts inlet condition outlet condition turbulent quantity wall condition

\section{References}

Aichouni M and Laribi B (2000). Computational Study of the Aerodynamic Behavior of the Laws Vaned Plate Flow Conditioner. Proceedings of the FEDSM2000 ASME Fluids Engineering Conference, Boston, USA.

Aichouni M, Laws EM and Ouazzane AK (1996). Experimental study of the effects of upstream flow condition upon venturi flow meter 
performance. Flow Modelling and Turbulence Measurements 6: 209-216.

Brown GJ and Griffith BW (2013). A New flow conditioner for 4-path ultrasonic flow meters. Proceedings of the FLOMEKO, Paris, France: 2426.

Elashmawy M and Kolsi L (2016). Turbulent forced convection heat transfer in triangular cross sectioned helically coiled tube. International Journal of Advanced and Applied Sciences, 3(7): 18-23.

Frattolillo A and Massarotti N (2002). Flow conditioners efficiency a comparison based on numerical approach. Flow Measurement and Instrumentation, 13(1): 1-11.

Gajan P, Hebrard P, Millan P, Giovannini A, Al Isber A, Strzelecki A and Trichet P (1991). Basic study of flow metering of fluids in pipes containing an orifice plate. Gas Research Institute Report, (5086-27), 1412.

Gersten K (2008). Flow metering with disturbed inflow. Acta Mechanica, 201(1-4): 13-22.

ISO 5167, (2014), Measurement of fluid flow by means of orifice plates nozzles and Venturi tubes inserted in circular cross-section conduits running full. JIS, (8762), 1991-2014 (R).

Laribi B and Abdellah Hadj A (2012). Analysis of turbulent flow development downstream disturbers with perforated plate flow conditioner.
In Applied Mechanics and Materials, Trans Tech Publications, 197(1): 73-77

Laribi B, Wauters P and Aichouni M (2003). Comparative study of aerodynamic behaviour of three flow conditioners. European Journal of Mechanical and Environmental Engineering, 48(1): 21-30.

Laws EM and Ouazanne AK (1994). Compact installations for differential flowmeters. Flow Measurement and Instrumentation, 5(2): 79-85.

Manshoor B and Khalid A (2012). Numerical investigation of the circle grids fractal flow conditioner for orifice plate flowmeters. In Applied Mechanics and Materials, Trans Tech Publications, 229: 700-704.

Merzkirch W and Strömungslehre L (2001). Flow metering in non-developed pipe flow. In $6^{\text {th }}$ Asian Symposium on Visualization, Pusan, Korea, Paper No. 171.

Morrison GL, DeOtte RE and Beam EJ (1992). Installation effects upon orifice flowmeters. Flow Measurement and Instrumentation, 3(2): 89-93.

Morrow TB, Park JT and McKee RJ (1991). Determination of installation effects for a $100 \mathrm{~mm}$ orifice meter using a sliding vane technique. Flow Measurement and Instrumentation, 2(1): 14-20.

Sawchuk D (2016). Fluid flow conditioning for flow meter accuracy and repeatability. CEESI North American Custody Transfer Measurement Conference, San Antonio, Texas, USA: 21-23. 